\title{
Application of Electro-Oxidation Method for Treatment of Dye Textile Wastewater Using Stainless Steel Electrode: Study of Electrolyte Concentration Effect to Color Removal
}

\author{
Jumardin Rua ,Yulan, Mega Maghfirotul Fajrin, Zaina Rohayati, Riyanto $^{* *}$ \\ Department of Chemistry, Faculty of Mathematics and Natural Sciences, Islamic University \\ of Indonesia, Yogyakarta, 55584, Indonesia. \\ *email: mhardinrua@gmail.com \\ email: riyanto@uii.ac.id
}

\begin{abstract}
The increasing number of textile industries creates new problems of environmental pollution from waste produced. Entering of concentrated wastewater that containing of complex organic compounds to agricultural land and rivers has caused loss to humans or the environment. Treatment of dye textile wastewater by electro-oxidation method using stainless steel electrode has been done. This research was conducted by two steps: characterization of electrode composition by using SEM-EDX, electrolysis of wastewater at variation of electrolyte concentration. The result shows that the electrode composition consisted of iron, chromium, nickel and silica with the main composition of iron in the amount of $72.2 \%$. After electrolysis on variations of electrolyte concentration and analysis of color removal percentage of wastewater, obtained that the largest of color removal percentage on the use of electrolyte concentration of $3 \%$ in the amount of $98.81 \%$
\end{abstract}

Keywords: electro-oxidation, dye, stainless steel, electrolyte

\begin{abstract}
ABSTRAK
Peningkatan jumlah industri tekstil telah menimbulkan masalah baru yaitu pencemaran lingkungan dari limbah yang dihasilkan. Masuknya limbah cair berwarna pekat yang mengandung senyawa organik kompleks ke lahan pertanian dan sungai telah menimbulkan kerugian terhadap manusia ataupun lingkungan. Pada penelitian ini, pengolahan limbah cair pewarna tekstil telah dilakukan dengan metode elektro-oksidasi menggunakan elektroda stainless steel. Penelitian ini terdiri atas dua tahap: karakterisasi elekktroda dengan SEM-EDX dan elektrolisis limbah pada variasi konsentrasi elektrolit pada degradasi warna limbah. Hasil penelitian menunjukkan elektroda yang digunakan memiliki komposisi berupa besi, kromium, nikel dan silika dengan komposisi utama yaitu besi sebesar $72.2 \%$. Setelah dilakukan elektrolisis pada berbagai variasi konsentrasi elektrolit dan analisis persentasi degradasi warna limbah didapatkan persentase terbesar yaitu pada penggunaan konsentrasi elektrolit 3\% sebesar $98.81 \%$.
\end{abstract}

Kata kunci: elektro-oksidasi, pewarna, stainless steel, elektrolit

Application of Electro-Oxidation Method for Treatment of Dye Textile Wastewater Using 147 Stainless Steel Electrode: Study of Electrolyte Concentration Effect to Color Removal 


\section{Pendahuluan}

Tekstil merupakan salah satu sektor industri yang menjadi andalan Indonesia sebagai sumber pendapatan negara, sehingga pemerintah menargetkan sektor ini dapat terus bertumbuh. Di Indonesia, usaha pada sektor ini telah menjamur baik untuk skala rumahan ataupun industri. Beberapa industri tekstil yang terkenal di Indonesia terdapat di kota Solo, Yogyakarta dan Pekalongan. Christian, dkk., (2007) telah melaporkan bahwa Industri tekstil mampu berkembang dengan pesat yaitu mencapai $0,85 \%$ per tahun.

$$
\text { Dampak dari perkembangan }
$$
tersebut memunculkan sebuah dugaan terhadap peningkatan besar volume limbah yang dihasilkan. Tahapan terpenting pada industri tekstil adalah proses pewarnaan kain. Pada proses tersebut digunakan air dan bahan pewarna sintetik dalam jumlah besar (Riyanto, 2013). Pewana sintetik dalam bentuk cair biasanya hanya digunakan untuk beberapa kali proses pewarnaan, selebihnya akan menjadi limbah

Limbah cair yang dibuang ke lingkungan dapat menyebabkan pencemaran air dan bersifat toksik bagi bioindikator (ganggang dan ikan) serta menurunkan koefisien nilai nutrisi (syarat kelayakan konsumsi) dari ikan (Pratiwi, 2010). Tercemarnya air oleh limbah cair industri tekstil sebagaimana yang dikemukakan oleh Sun, dkk., (2015) bahwa limbah tersebut mengandung mengandung amoniak dan senyawasenyawa organik. Nugroho dan Ikbal (2005) menambahkan bahwa limbah cair industri tekstil mengandung bahan pencemar organik yang dinyatakan dalam COD, BOD dan logam-logam berat, serta bahan pewarna organik rantai panjang yang relatif sukar diolah dengan proses biologis biasa.

Menurut beberapa hasil penelitian limbah tekstil memiliki komposisi dan karakteristik yang ditampilkan pada Tabel 1. Air limbah yang mengandung polutan bahan organik zat warna rantai panjang yang biasa digunakan pada industri tekstil seperti senyawa azo, antraquinon dan juga ftalosianin tidak dapat dengan mudah diolah dengan proses biologis biasa (Nugroho dan Ikbal, 2005). Besarnya biaya yang harus dikeluarkan oleh para perajin dan ketidakmampuan metode pengolahan yang telah disebutkan diatas telah menyebabkan limbah tersebut akhirnya dibuang ke linkungan. 
Tabel 1. Komposisi dan karakterisasi limbah industri tekstil

\begin{tabular}{ccccc}
\hline Parameter & $\begin{array}{c}\text { Zodi, dkk., } \\
(2009)\end{array}$ & $\begin{array}{c}\text { Akanksha, } \\
\text { dkk., }(2013)\end{array}$ & $\begin{array}{c}\text { Manenti, } \\
\text { dkk., (2014) }\end{array}$ & $\begin{array}{c}\text { Mukimin, } \\
\text { dkk., }(2015)\end{array}$ \\
\hline BOD $(\mathrm{mg} / \mathrm{L})$ & - & 2.674 & 2.00 & 44,54 \\
COD $(\mathrm{mg} / \mathrm{L})$ & 3.260 & $\begin{array}{c}12.900 \text { dan } \\
17.800\end{array}$ & 1.200 & 470 \\
pH & 7 & 4,68 & 11,3 & 11,7 \\
Konduktivitas & 1,9 & - & 18 & - \\
(mg/cm) & & & & - \\
Nitrat (mg/L) & - & 5,28 & 3,3 & - \\
Klorida (mg/L) & - & $1.99,93$ & 5.500 & 0,757 \\
Sulfat (mg/L) & - & 8,98 & 119 & - \\
Fosfat (mg/L) & - & 39,40 & $<0,2$ & $<0,03$ \\
Total krom (mg/L) & - & - & - & \\
\hline
\end{tabular}

Metode alternatif pengolahan limbah industri seperti tekstil yang dianggap lebih menguntungkan dan banyak digunakan adalah proses pengolahan limbah dengan menggunakan metode elektrolisis. Metode ini dianggap sangat sesuai untuk mengolah limbah tekstil yang banyak mengandung zat warna organik, karena degradasi di anoda akan mudah terjadi. Selain itu, metode elektrolisis tidak memerlukan bahan-bahan kimia tambahan, tidak memerlukan proses pemisahan katalis dan cara penggunaan yang mudah (Riyanto, 2013).

Pada penelitian ini pengolahan limbah cair tekstil dilakukan dengan metode elektrolisis menggunakan elektroda stainless steel. Pemilihan elektroda tersebut didasarkan pada alloy yang terdiri atas tiga logam yaitu $\mathrm{Cr}, \mathrm{Ni}$ dan Mg. Penggunaan tiga logam sekaligus akan lebih baik bila dibandingkan dengan Application of Electro-Oxidation Method for Treatment of Dye Textile Wastewater Using 149 Stainless Steel Electrode: Study of Electrolyte Concentration Effect to Color Removal satu logam. Hal ini disebabkan karena akan terjadi synergistic effect diantara ketiga logam. Selain itu elektroda yang mengandung dua logam atau lebih akan memiliki dua atau lebih sisi aktif yang berperan sebagai katalis elektrokimia dalam degradasi senyawa organik (Riyanto, 2013).

\section{Tujuan Penelitian}

Tujuan penelitian ini adalah untuk mempelajari pengaruh konsentrasi elektrolit $\mathrm{NaCl}$ terhadap persentase degradasi warna limbah.

\section{Metode Penelitian}

\section{Bahan Penelitian}

Bahan-bahan yang digunakan dalam penelitian ini terdiri atas limbah cair tekstil dari salah satu industri rumahan (home industry) di kota Yogyakarta, elektrolit sodium klorida, logam stainless steel dan akuades. 


\section{Peralatan Penelitian}

Peralatan penunjang yang digunakan dalam penelitian ini terdiri atas alat-alat gelas seperti gelas beker, corong dan kaca arloji, magnetic stirrer (HMS79), sendok sungu, neraca elektrik $\left(O H A U S^{\circledR}\right)$, spektrofotometer UV-Visible (HITACHI U-2010) dan Scanning Electron Microscopy-Energy DispersiveX-Ray $\left(\right.$ Phenom $^{\mathrm{TM}}$ ).

\section{Prosedur Penelitian}

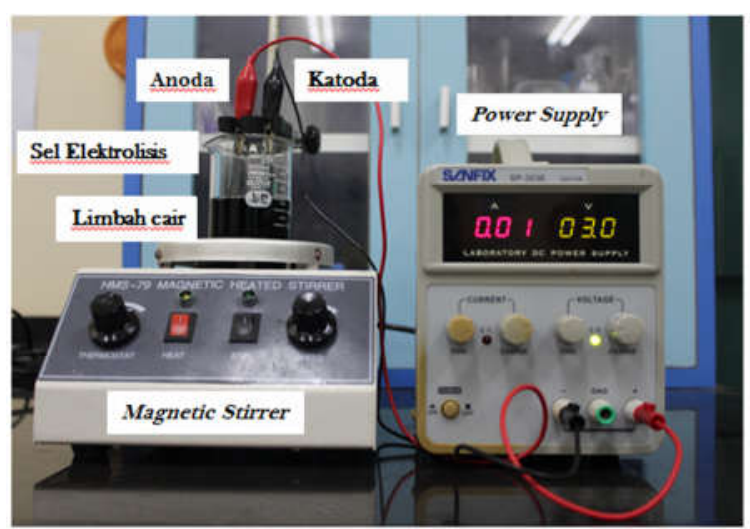

Gambar 1. Rangkaian alat elektrolisis dalam penelitian

\section{Preparasi dan Analisis Komposisi Elektroda}

Elektroda stainless steel yang digunakan dalam penelitian ini berbentuk plat dengan luas permukaan $7,5 \times 2 \mathrm{~cm}^{2}$, sedangkan yang tercelup dalam larutan limbah cair tekstil adalah $1,5 \times 2 \mathrm{~cm}^{2}$. Analisis komposisi stainless steel yang digunakan sebagai elektroda untuk mengetahui komposisi unsurnya.
Elektrolisis Limbah Cair Tekstil dan Analisis Secara Spektrofotometri

Tahapan elektrolisis dalam penelitian ini yaitu dimasukkan $50 \mathrm{~mL}$ limbah cair tekstil dalam sel elektrolisis dengan potensial sebesar $3 \mathrm{~V}$ dan waktu elektrolisis selama 60 menit. Proses elektrolisis dilakuakn dengan variasi konsentrasi elektrolit yaitu $1 ; 1,4 ; 1,8 ; 2,2$; 2,6 dan 3\%. Hasil elektrolisis pada variasi tersebut kemudian dianalisis secara spektrofotometri pada panjang gelombang 200-800 nm. Hasil analisis berupa nilai absorbansi dapat digunakan untuk menghitung persentase degradasi warna limbah setelah dielektrolisis pada variasi tersebut. Selanjutnya untuk menentukan kondisi terbaik pada variasi ini dapat dilihat pada spektra hasil analisis yang memiliki nilai absorbansi terendah dan persentase degradasi terbesar. Persentase degradasi warna limbah dapat dihitung dengan menggunakan persamaan:

$$
\mathrm{R} \%=\left[100\left(\mathrm{~A}_{0, \lambda}-\mathrm{A}_{1, \lambda}\right)\right] / \mathrm{A}_{0, \lambda}
$$

dimana,

$\mathrm{R} \%=$ Persentase degradasi warna limbah, $\mathrm{A}_{0, \lambda}=$ Absorbansi limbah cair tekstil (400

$\mathrm{nm})$ dan

$\mathrm{A}_{1, \lambda}=$ Absorbansi limbah cair tekstilsetelah dielektrolisis pada berbagai variasi $(400 \mathrm{~nm})$ 


\section{Pembahasan}

\section{Komposisi Elektroda}

Komposisi elektroda stainless steel dapat diketahui dari hasil analisis menggunakan SEM-EDX. Spektra hasil analisis EDX ditunjukkan pada Gambar 2.

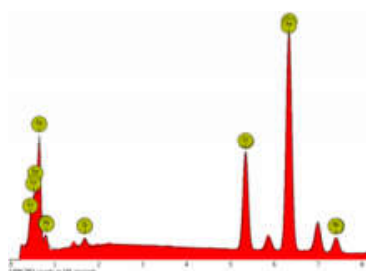

Gambar 2. Spektra hasil analisis EDX elektroda stainless steel

Berdasarkan spektra hasil analisis pada gambar 2 menunjukkan bahwa elektroda tersebut terdiri atas beberapa logam dengan komposisi utama adalah unsur besi. Adapun kadar dari masing-masing unsur dapat dilihat pada Tabel 2.

Tabel 2. Komposisi unsur logam dalam elektroda stainless steel

\begin{tabular}{ccc}
\hline Unsur logam & $\begin{array}{c}\text { Nomor } \\
\text { atom }\end{array}$ & Kadar (\%) \\
\hline Besi (Fe) & 26 & 72,2 \\
Krom (Cr) & 24 & 18,9 \\
Nikel (Ni) & 28 & 7,6 \\
Silika (Si) & 14 & 1,4 \\
\hline
\end{tabular}

\section{Pengaruh Konsentrasi Elektrolit}

Elektrolit $\mathrm{NaCl}$ berperan sebagai penghantar arus listrik dalam larutan, sehingga degradasi terhadap senyawa organik dapat berlangsung lebih cepat. Variasi konsentrasi elektrolit bertujuan untuk mengetahui pengaruhnya terhadap persentase degradasi warna limbah. Degradasi warna limbah tekstil dari sebelum hingga sesudah elektrolisis dapat dilihat pada Gambar 3.

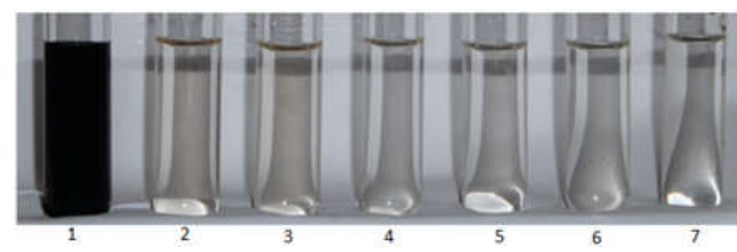

Gambar 3. Degradasi warna limbah tekstil dari kiri ke kanan: tanpa elektrolisis (1) hingga elektrolisis pada variasi konsentrasi elektrolit $\mathrm{NaCl}$ secara berturut-turut

Berdasarkan Gambar 3 secara visual dapat dilihat bahwa perubahan warna larutan limbah tekstil mulai terlihat pada penggunaan konsentrasi elektrolit $1 \%$. Selanjutnya larutan limbah tekstil yang telah dielektrolisis paling jernih yaitu pada penggunaan konsentrasi elektrolit 1.8 hingga 3\%. Berdasarkan hal tersebut maka dapat diketahui bahwa konsentrasi elektrolit berbanding lurus dengan degradasi warna terhadap limbah tekstil secara visual. Hal ini kemungkinan diakibatkan meningkatnya jumlah agen pengoksidasi seperti $\mathrm{Cl}_{2}, \mathrm{HClO}$, dan $\mathrm{ClO}^{-}$ dalam larutan limbah pewarna tekstil yang mengoksidasi senyawa-senyawa organik. Agen pengoksidasi tersebut dapat berasal dari ion klorida $\left(\mathrm{Cl}^{-}\right)$dari peruraian 
elektrolit $\mathrm{NaCl}$ dalam larutan yang kemudian mengalami reaksi lebih lanjut. Hasil analisis spektra UV- Vis dapat dilihat pada Gambar 4.

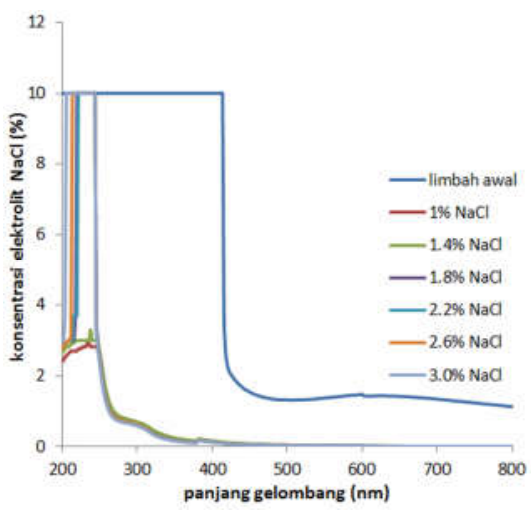

Gambar 4. Spektra UV- Vis pada variasi massa elektrolit $\mathrm{NaCl}$
Spektra UV- Vis pada Gambar 4 menunjukkan semakin meningkatnya nilai absorbansi pada daerah ultraviolet (200$400 \mathrm{~nm}$ ) seiring dengan bertambahnya konsentrasi elektrolit yang digunakan. Hal ini diakibatkan oleh terbentuknya senyawa-senyawa sederhana pada daerah ultraviolet. Menurut Riyanto (2013) senyawa tersebut kemungkinan adalah benzene, kloro benzene atau dikloro benzene. Persentase degradasi warna limbah pada variasi konsentrasi elektrolit dapat dilihat pada Tabel 2.

Tabel 2. Persentase degradasi pada variasi konsentrasi elektrolit

\begin{tabular}{cccccc}
\hline $\begin{array}{c}\text { waktu } \\
\text { elektrolisis } \\
\text { (menit) }\end{array}$ & $\begin{array}{c}\text { Potensial } \\
(\mathrm{V})\end{array}$ & $\begin{array}{c}\text { Konsentrasi } \\
\text { elektrolit (\%) }\end{array}$ & \multicolumn{3}{c}{ Persentase degradasi warna } \\
\cline { 3 - 6 } & & & awal (abs) & akhir (abs) & \% Degradasi \\
\hline \multirow{2}{*}{60} & 3 & 1,4 & 10 & 1,622 & 98,65 \\
& 3 & 1,8 & 10 & 0,904 & 98,37 \\
& & 2,2 & 10 & 0,238 & 98,72 \\
& & 2,6 & 10 & 0,181 & 98,64 \\
& 3,0 & 10 & 0,144 & 98,71 \\
\hline
\end{tabular}

\section{Kesimpulan}

Setelah dilakukan elektrolisis pada variasi konsentrasi elektrolit dan analisis persentasi degradasi warna limbah didapatkan persentase terbesar yaitu pada penggunaan konsentrasi elektrolit 3\% sebesar $98.81 \%$.

\section{Daftar Pustaka}

Akanksha, Roopashree, G., B., dan Lokesh, K., S., 2013, Comparative Study of Electrode Material (Iron, Aluminium and Stainless Steel) for
Treatment of Textile Industry Wastewater, International Journal of Environmental Sciences, 4,4, 523-524

Christian, H., Suwito, E., Ferdian, T., A., Setiadi, T., dan Suhardi, S., H., 2007, Kemampuan Pengolahan Warna Limbah Tekstil oleh Berbagai Jenis Fungi dalam Suatu Bioreaktor, Seminar Nasional Fundamental dan Aplikasi Teknik Kimia, Jurusan Teknik Kimia FTIITS, Surabaya 
Manenti, D., R., Modenes, A., N., Soares, P., A., Quinones, F., R., E., Boaventura, R., A., R., Bergamasco, R., dan Vilar, V., J., P., 2014, Assessment of a Multistage System Based on Electrocoagulation, Solar PhotoFenton and Biological Oxidation Processes for Real Textile Wastewater Treatment, Chemical Engineering Journal, 251, 120-130

Mukimin, A., Vistanty, H., dan Zen N., 2015, Oxidation of Textile Wastewater Using Cylinder $\mathrm{Ti} / \beta$ $\mathrm{PbO}_{2}$ Electrode in Electrocatalytic Tube Reactor, Chemical Engineering Journal, 259, 430-437

Nugroho, R. dan Iqbal, 2005, Pengolahan Air Limbah Berwarna Industri Tekstil dengan Proses AOPs, JAI, $1,2,163-172$

Pratiwi, Y., 2010, Penentuan Tingkat Pencemaran Limbah Industri Tekstil Berdasarkan Nutrition Value Coeficient Bioindikator, Jurnal Teknologi, 3, 2, 129

Riyanto, 2013, Elektrokimia dan Aplikasinya, Graha Ilmu, Yogyakarta

Sun, F., Sun B., Hu, J., He, Y., dan Wu, W., 2015, Organics and Nitrogen Removal from Auxiliaries Wastewater with $\mathrm{A}^{2} \mathrm{O}-\mathrm{MBR}$ in a Pilot-Scale, Journal of Hazadous Material 286, 416

Zodi, S., Potier, O., Lapicque, F., dan Leclerc, J., P., 2009, Treatment of the Textile Wastewaters by Electrocoagulation: Effect of Operating Parameters on the Sludge Settling Characteristics, Separation and Purification Technology, 69, 29-36

Application of Electro-Oxidation Method for Treatment of Dye Textile Wastewater Using 153 Stainless Steel Electrode: Study of Electrolyte Concentration Effect to Color Removal 